\title{
The Physician Order for Standardized Concentration of Adult's Electrolyte Replacement Therapy: New Initiative in Saudi Arabia
}

\begin{abstract}
Yousef Ahmed Alomi* $(\mathbb{D}$, The
Former General Manager of General Administration of Pharmaceutical Care and Head, National Clinical pharmacy, and Pharmacy Practice and Pharmacy R \& D Administration, $\mathrm{MOH}$, Riyadh, KSA.

Manal Mansour Al Nemari,

Supervisor, Pharmacy Informatics and Automation, King Fahad Medical City, Riyadh, Saudi Arabia.

Fatimah Al-Doughan, College of Pharmacy, Pharmacy Practice Department, King Faisal University, Alhassa, Saudi Arabia. Yasir Ahmed Ibrahim, Head of Pharmacy Practice Department, Pharmacy Practice Department, College of Clinical Pharmacy, King Faisal University, Alahssa, Saudi Arabia.

Hussam Saad Almalki, Supervisor of IV Admixture Services, Aleman Hospital, $\mathrm{MOH}$, Riyadh, KSA.

Nahedh Rashed Alotaibi, Head, Pharmacy services, Aleman Hospital, MOH, Riyadh, KSA.
\end{abstract}

Mona Mustafa Jadkarim, Supervisor of inpatient pharmacy, Pharmacy services, Aleman Hospital, MOH, Riyadh, KSA.

\section{Correspondence:}

Dr. Yousef Ahmed Alomi, The Past General Manager of General Administration of Pharmaceutical Care Head, National Clinical pharmacy, and Pharmacy Practice Programs Head, Pharmacy R \& D Administration Ministry of Health, P.O.BOX 100, Riyadh 11392, Riyadh, SAUDI ARABIA.

Phone no: +966 504417712

E-mail:yalomi@gmail.com

\section{Received: 06-04-2019;}

Accepted: 16-06-2019

Copyright: $\odot$ the author(s), publisher and licensee International Journal of Pharmacology and Clinical Sciences. This is an open-access article distributed under the terms of the Creative Commons Attribution Non-Commercial License, which permits unrestricted non-commercial use, distribution, and reproduction in any medium, provided the original work is properly cited.

This is an open access article distributed under the terms of the Creative Commons Attribution-NonCommercial-ShareAlike 4.0 License

Access this article online

\begin{tabular}{|c|c|}
\hline & www.ijpcs.net \\
\hline & \\
\hline
\end{tabular}

\section{ABSTRACT}

The electrolyte replacement therapy consternation considered one of the high alert drugs. Most of the medication safety organizations have established preventive guidelines for the prescription of electrolyte therapy. The General Administration of Pharmaceutical Care at the Ministry of Health in the Kingdom of Saudi Arabia also has established guidelines for the preparation and administration of electrolyte replacement for adult patients. This new initiative is regarding the standardized concentration of electrolyte preparation and administration for adult patients. The electrolyte therapy may be prescribed via a physician order form, which may be easily converted as computerized physician order entry. This from is designed to prevent all electrolyte-related errors and improve patient outcomes. This project is a new tool implemented for electrolyte safety at the Ministry of Health hospitals in the Kingdom of Saudi Arabia. Keywords: Adult, Physician order, Standardized Concentration, Electrolyte, Ministry of Health, Saudi Arabia.

\section{INTRODUCTION}

The general administration of pharmaceutical care established in the past several pharmacy practice program including National Intravenous admixture program(1)(2)during author study at the college of pharmacy at King Saud University, the last year of studying required practice training at the hospital pharmacy. The author spent his training at King Faisal Specialist Hospital and Research Center (KFSH\&RC. The program consisted of the design of IV admixture setting, application of USP 797 of regular medications and USP 800 standards of chemotherapy medications(3)(4). In addition, several booklets of the standardized concentration of medications for adults and pediatrics including the electrolyte and released in 2015(5)(6). The national accreditation organization and international one considered the electrolyte as high alert medications(7). Also, the ISMP published several publications about high alert medications with the emphasis on the electrolyte(8)(9). Three hospitals in Riyadh city in Saudi Arabia established new initiatives program of medications safety related issues and designed adult's standardized concentration of electrolyte physician order. That is a project to prevent any mistakes of the electrolyte with different concentration and improve the patient outcome of drug therapy(10)safety, and nursing acceptability of a nursing initiated, evidence-based order form to replace potassium, magnesium, and phosphate in the MICU. Methods: This retrospective study compared patients receiving electrolyte replacement with the order form to matched historical control patients receiving traditional electrolyte replacement (no order form(11). The authors are not familiar with any investigations in Saudi
Arabia or Gulf and Middle East counties. The project the first times one founded in Arabic area

\section{Adults Electrolyte Replacement Therapy order in Saudi Arabia}

It standardized formulation of electrolyte requirements for adults. The formulation drove from current literature and guidelines for adult's population with an average of seventykilogram body weight. The electrolyte consisted of Potassium, Magnesium, Calcium, and Phosphate. The physician order form consisted of several parts demographic data of the patients, the laboratory level for each element of the electrolyte, the standardized concentration and maximum concentration, the type of crystallized fluid, the administration type through a central or peripheral vein, the dosing range requirements as explored in physician order forms appendix 1,2,3,4.

\section{SWOT Analysis}

The SWOT (Strength, Weakness, Opportunities, and Threads) used for benefit and risk of the project. The strength of the adult's physician order forms including all information of common electrolyte is available, dosing of medications is available, fixed standardized concentration of the electrolyte is available, the method of electrolyte administration is available, and prevent mistakes in writing electrolyte orders for adults. The weakness points are including it cannot apply to several disease renal or hepatic failure. The opportunity that is including it very easy to form to convert them into computerized and physician order entry; it can calculate all electrolyte statistical information. The third 
points including the physician or pharmacist have not used the standardized concentration of the electrolyte.

Implementations steps of Adults Electrolyte Replacement standardized concentration

The pharmacy department Organize Consultation Committee from expert pharmacist especially from Intravenous admixture and total parental nutrition services and critical care clinical pharmacists inside the pharmacy department. The committee should extensive review then approve the standardized concentration of Adults Electrolyte replacement. The head of the committee will contact with the surgical and medical department for final revisions of the drafting and approval. The head of pharmacy services will submit the final draft of the formulation to Pharmacy and Therapeutic committee for review and approval. The head of the committee will arrange with Computer department to make as electronic order forms as explored in figure 1 . The pharmacy education coordinator arranges with all department including nursing, surgical and medical department to Educate and train the medical staff of using the formulation with additional to pharmacy staff. The pharmacy quality management will set up the key performance indicators (KPI) to measure the impact of the project. All pharmacy concern team including electrolytes Preparation, clinical pharmacist will Collect the KPI of the project retrospectively in the past three to six months. Then collect the data prospectively in the coming months. The head of the committee will contact with musing and surgical development to start with one surgical department as the pilot trial. The pharmacist will Review the pilot trial and correct the form accordingly the pharmacy consultation committee. The team will expand to all surgical department and medical department. Review and alter the shape accordingly through committee. The head of the committee will Expand to all hospital department including adults critical care, Review and adjust the formulation accordingly. The pharmacy quality management coordinator measure the impact of the project by comparing the KPI before and starting the project. The head of the committee will analyze the results and review by the consultation committee. The head of the pharmacy will submit the final report to Pharmacy and therapeutic comments for final touch and comments. The consultation team Review the last comments on the project, update it accordingly, and continue the project for next year as explored in table 1.

\section{CONCLUSION}

The adults electrolyte standardized concentration is new tool of medications safety. The new

\section{Potassium chloride}

POIASSIUM THLORIDE (2UM|MOLTUUML DEXIROSE 5\% CEENIERAL LINE.

POTASSIUM CHLORIDE (20MMOL/100ML NORMAL SALINE) CENTERAL LINE.

POTASSIUM CHLORIDE (20MMOL/500ML NORMAL SLINE) PERIPHERAL LINE. POTASSIUM CHLORIDE (30MMOL/100ML DEXTROSE 5\%) CENTERAL LINE. POTASSIUM CHLORIDE (30MMOL/100ML NORMAL SALINE) CENTERAL LINE. POTASSIUM CHLORIDE (40MMOL/100ML DEXTROSE $5 \%$ ) CENTERAL LINE. POTASSIUM CHLORIDE (40MMOL/100ML NORMAL SALINE) CENTERAL LINE. POTASSIUM CHLORIDE (40MMOL/5OOML NORMAL SALINE) PERIPHERAL LINE.

\section{Potassium phosphate}

POTASSIUM PHOSPHATE ( $9 \mathrm{MMOL} / 100 \mathrm{ML}$ NORMAL SALINE) CENTERAL LINE POTASSIUM PHOSPHATE ( $12 \mathrm{MMOL} / 100 \mathrm{ML}$ DEXTROSE $5 \%$ ) CENTERAL LINE POTASSIUM PHOSPHATE (12 MMOL/100ML NORMAL SALINE) CENTRERAL LINE POTASSIUM PHOSPHATE (15 MMOL/100ML DEXTROSE 5\%) CENTERAL LINE POTASSIUM PHOSPHATE (15 MMOL/100ML NORMAL SALINE) CENTERAL LINE POTASSIUM PHOSPHATE ( $30 \mathrm{MMOL} / 100 \mathrm{ML}$ DEXTROSE $5 \%$ ) CENTERAL LINE POTASSIUM PHOSPHATE ( $30 \mathrm{MOOL} / 100 \mathrm{ML}$ NORMAL SALINE) CENTERAL LINE POTASSIUM PHOSPHATE (6 MMOL/10OML DEXTROSE 5\%) PERIPHERAL LINE POTASSIUM PHOSPHATE ( $6 \mathrm{MMOL} / 100 \mathrm{ML}$ NORMAL SALINE) PERIPHERAL LINE POTASSIUM PHOSPHATE ( 9 MMOL/10OML DEXTROSE) CENTERAL LINE

\section{Magnesium sulfate}

\begin{tabular}{ll} 
MAGNESILM SLIFATE (2G/100ML DEXTROSE 5\%) & 000096095 \\
\hline MAGNESIUM SULFATE (2G/100ML NORMAL SALINE) & 000096096 \\
MAGNESIUM SULFATE (4G/100ML DEXTROSE 5\%) & 00009609 \\
MAGNESIUM SULFATE (4G/100ML NORMAL SALINE) & 000096098 \\
MAGNESIUM SULFATE (6G/100ML DEXTROSE 5\%) & 000096096 \\
MAGNESIUM SULFATE (6G/100ML NORMAL SALINE) & 000096106 \\
MAGNESIUM SULFATE (8G/100 DEXTROSE 5\%) & $00009610:$ \\
MAGNESIUM SULFATE (8G/100ML NORMAL SALINE) & $00009610:$
\end{tabular}

\section{Calcium gluconate}

CALCIUM GLUCONATE ( 1 G/10OML DEXTROSE 5\%)

CALCIUM GLUCONATE (1G/100ML NORMAL SALINE)

CALCIUM GLUCONATE (2G/100ML DEXTROSE $5 \%$ )

CALCIUM GLUCONATE (2G/100ML NORMAL SALINE)

CALCIUM GLUCONATE (4G/10OML DEXTROSE 5\%)

CALCIUM GLUCONATE (4G/10OML NORMAL SLINE)

\section{Sodium phosphate}

SODILM PHOSPHATE (12 MMOLI10OML DEXTROSE 5\%) PERIPHERAL LINE

SODIUM PHOSPHATE (12 MMOL/100ML NORMAL SALINE) PERIPHERAL LINE

00009610.

SODIUM PHOSPHATE (15 MMOL/DEXTROSE 5\%) PERIPHERAL LINE

SODIUM PHOSPHATE (15 MMOL/100ML NORMAL SALINE) PERIPHERAL LINE

SODIUM PHOSPHATE ( $30 \mathrm{MMOL} / 100 \mathrm{ML}$ DEXTROSE 5\%) PERIPHERAL LINE

SODIUM PHOSPHATE (30 MMOL/100ML NORMAL SALINE) PERIPHERAL LINE

5ODIUM PHOSPHATE ( 9 MMOL/100ML DEXTROSE 5\%) PERIPHERAL LINE

SODIUM PHOSPHATE ( 9 MMOL/10OML NORMAL SALINE)

Figure 1: CPOE of Electrolyte Replacement Concentrations

initiatives project prevent an electrolyte related problem and improve patient clinical outcomes

\section{ORCID ID}

Yousef Ahmed Alomi org/0000-0003-1381-628X

\section{REFERENCES}

1. AlomiYA. National Pharmacy Practice Programs at Ministry of Health in Saudi Arabia. JPharm Pharm Scien. 2015;1(2):17-8.

2. Alomi YA. National Intravenous (IV) Therapy Program at $\mathrm{MOH}$ in Saudi Arabia. EC Pharm Sci.
2016;(2.3):307-11.

3. Notices G, Test BE, Compound- P, Practices C. (797) Pharmaceutical Compounding - Sterile Preparations. Design. 2007;5(Class 100):1-61.

4. Pharmacopeia US. USP General Chapter <800> Hazardous Drugs- Handling in Healthcare Settings. United States Pharmacop. 2017;

5. Alomi, Yousef et al. Adult Parenteral Dilution Manual [Internet]. $1^{\text {st }}$ Editio. General Adminstration of Pharmaceutical care, $\mathrm{MOH}$, Saudi Arabia 2015. Available from: https://www.researchgate net/publication/281710454_Adults_Parenteral_Dilution_Manual

6. Yousef A. et al. Pediatrics Parenteral Dilution Manual [Internet]. 1st Editio. General Adminstration of Pharmaceutical care, MOH, Saudi Arabia; 2015. 


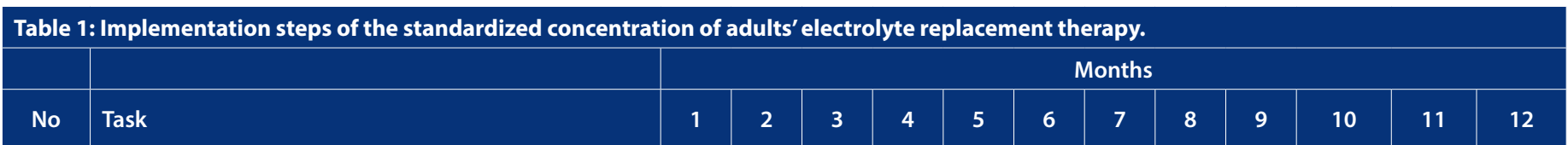

1 Organize Consultation Committee from expert

pharmacist inside the pharmacy department

2 Review and approve the standardized concentration form of Adults Electrolyte replacement

3 Contact with the surgical and medical department for final revisions of the physician order form and approval

Submit the final draft of the physician order form to

4 Pharmacy and the Therapeutic committee for revision and approval

5 Arrange with Computer department to make as electronic order forms

$6 \quad$ Educate and train the pharmacy and medical staff of using the physician order form

7 Setup the key performance indicators (KPI) to measure the impact of the project

Collect the KPI of the project retrospectively in the

8 past three to six months. Moreover, collect the data prospectively in the coming months

9 Start with one surgical department as a pilot trial

10 Review the pilot trial and correct the form accordingly

11 Expand to all surgical department and medical department

12 Review and correct the form accordingly

13 Expand to all hospital department including adults critical care

14 Review and correct the formulation accordingly

15 Measure the impact of the project by comparing the KPI before and starting the project

16 Analyze the results and submit the final report to Pharmacy and therapeutic comments

17 Review the final comments on the project and update it 17 accordingly and continue the project with next year

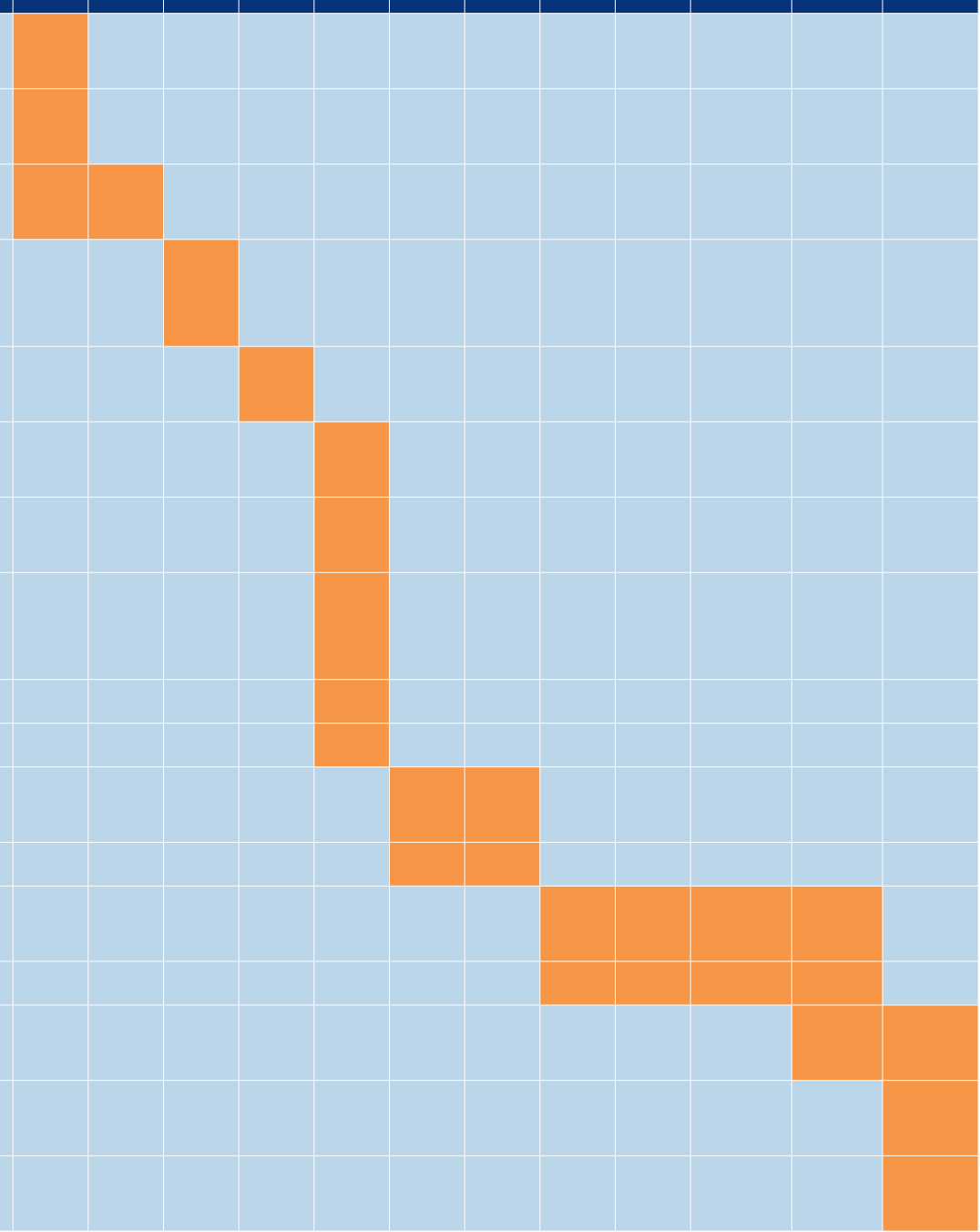

Available from: https://www.researchgate.net/ publication/281710402_Pediatrics_Parenteral_Dilution_Manual

7. Medication Management (MM). In: National Hospital Standards [Internet]. 2nd Editio. Saudi Central Board for Accreditation of Healthcare Institutions.; 2015. p. 194-211. Available from: http:// www.cbahi.gov.sa

8. ISMP Medication Safety Self Assessment $®$ for
High-Alert Medications General High-Alert Medications Neuromuscular Blocking Agents Concentrated Electrolytes Injection Magnesium Sulfate Injection Moderate Sedation in Adults and Children, Minimal Sedation in

9. Institute for Safe Medication Practices. 2011 ISMP Medication Safety Self Assessment for Hospitals, Key Definitions. 2011;1-4. Available from: http:// ismp.org/selfassessments/Hospital/2011/defini- tions.pdf

10. Owen P, Monahan MF, MacLaren R. Implementing and assessing an evidence-based electrolyte dosing order form in the medical ICU. Intensive Crit Care Nurs. 2008;24(1):8-19.

11. Couture J, Létourneau A, Dubuc A, Williamson D. Evaluation of an electrolyte repletion protocol for cardiac surgery intensive care patients. Can J Hosp Pharm. 2013. 


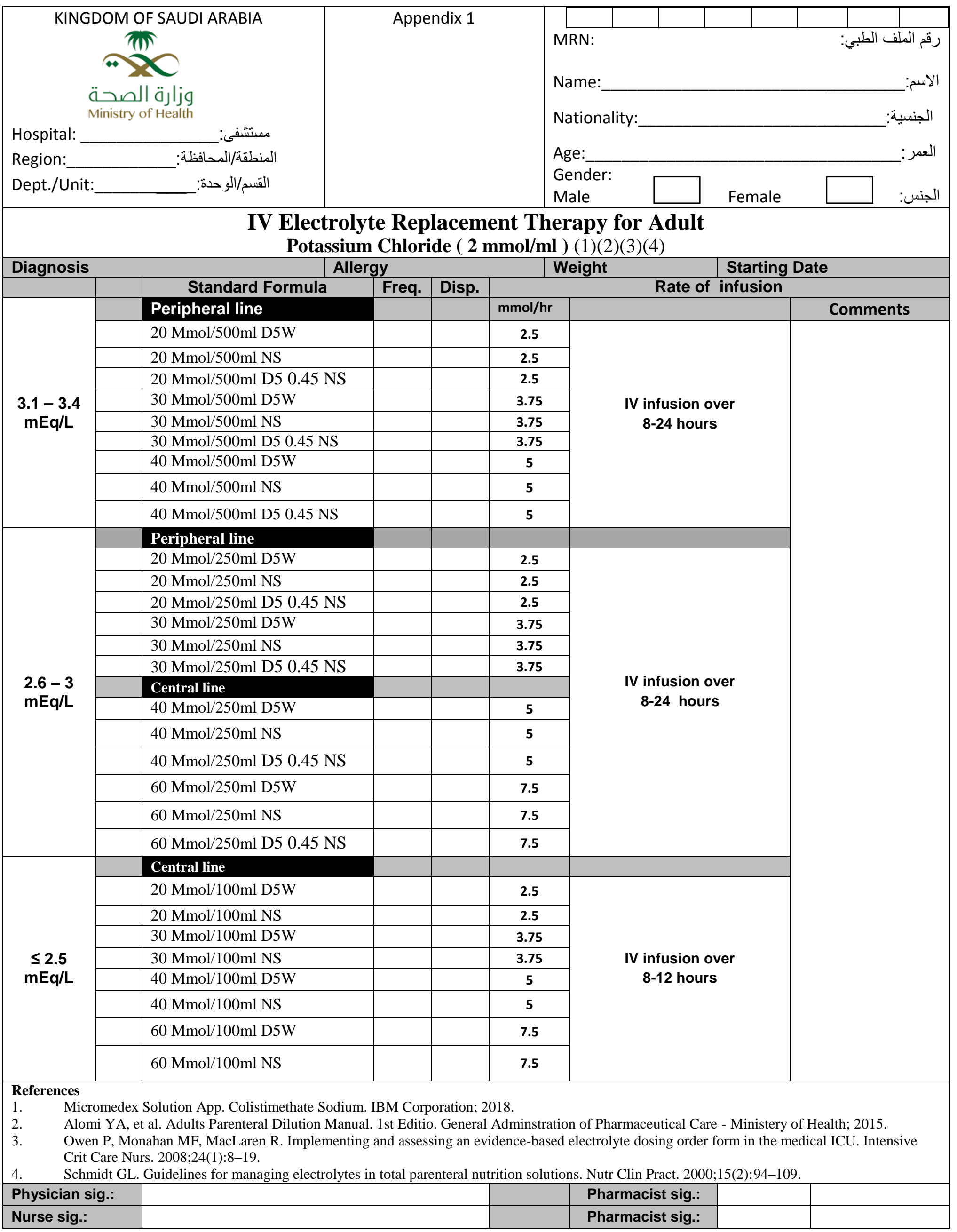




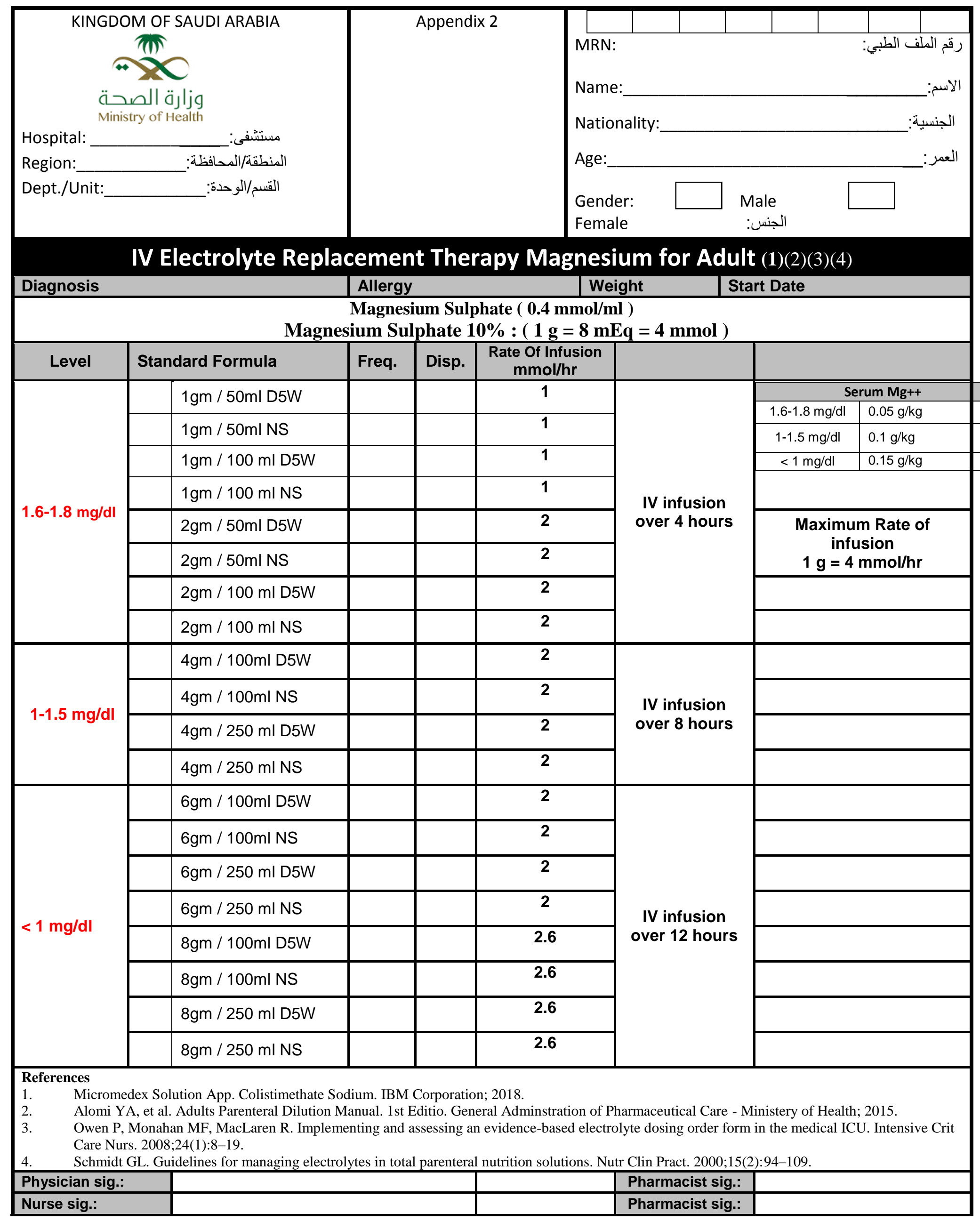




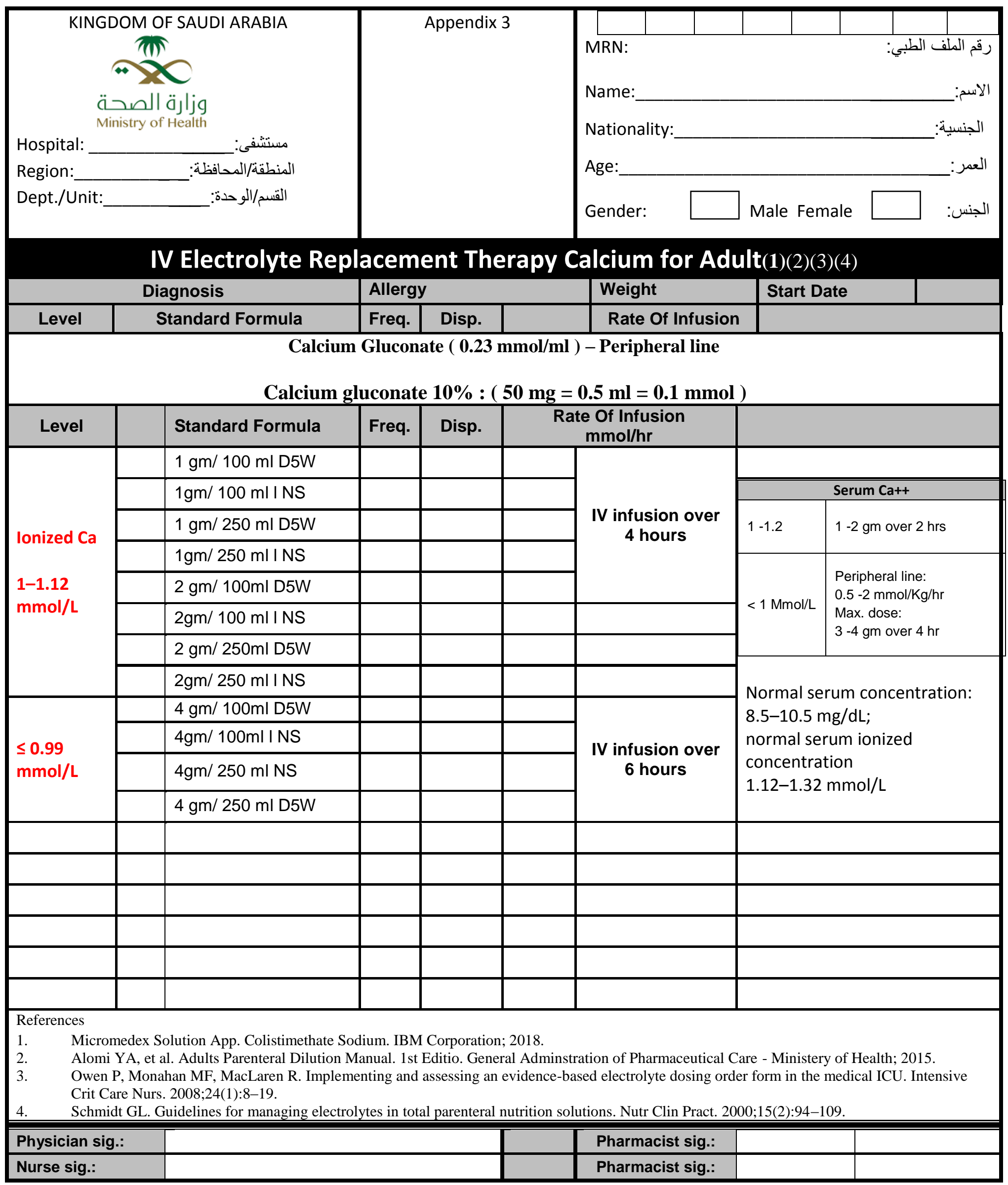




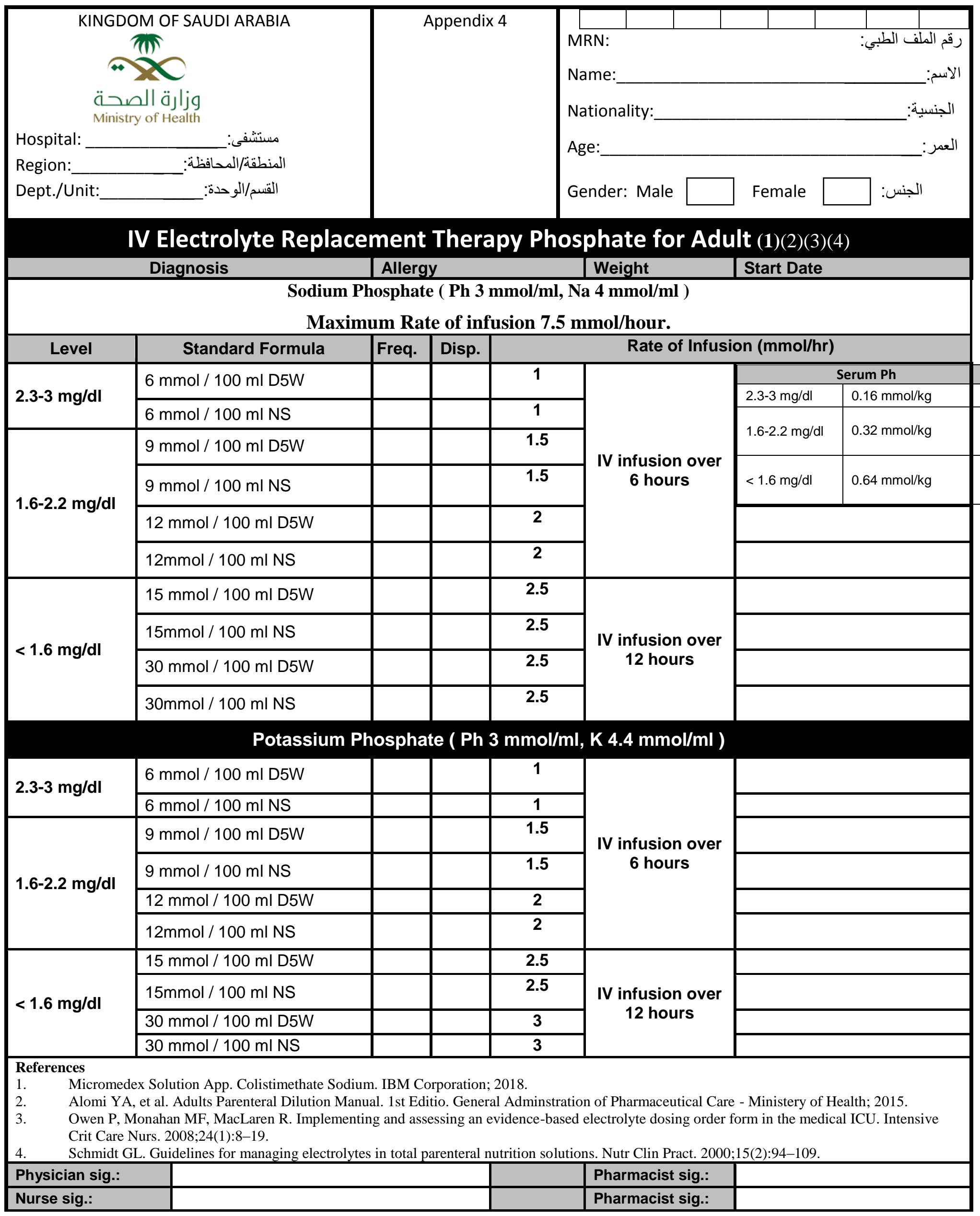

